\title{
Effect of Trace Element on Microstructure and Fracture Toughness of Weld Metal
}

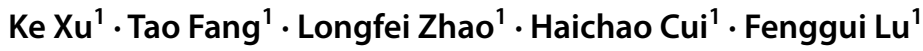

Received: 27 August 2019 / Revised: 20 October 2019/ Published online: 17 December 2019

(C) The Chinese Society for Metals (CSM) and Springer-Verlag GmbH Germany, part of Springer Nature 2019

\begin{abstract}
The microstructure and fracture toughness of weld metal under Ti-free and Ti-containing different fluxes were investigated in this study. It was found that the trace element Ti of flux in submerged arc welding produced significant influence on the fracture toughness. The addition of $60 \mathrm{ppm}$ Ti induced the sharp increase in $J_{0.2}$ value from 232.78 to $364.08 \mathrm{~kJ} / \mathrm{m}^{2}$. Microstructure characterization revealed that a large number of oxide inclusions prompted the nucleation of acicular ferrites and refined grains, which improved the fracture toughness of Ti-containing weld metal greatly. Moreover, the crack propagation path was more tortuous and bifurcated due to the small amount of carbide precipitations along grain boundaries and blocky martensite-austenite islands for Ti-containing weld metal. Meanwhile, the large-angle grain boundaries caused crack deflection and increased the resistance of crack propagation compared to Ti-free weld metal.
\end{abstract}

Keywords Fracture toughness $\cdot$ Microstructure $\cdot$ Weld metal $\cdot$ Trace element $\cdot$ Crack propagation

\section{Introduction}

As a clean energy alternative to thermal power, the development of nuclear power presents a significant effect on energy structure adjustment and power generation efficiency [1,2]. The rotors in steam turbines are subjected to large thermal stresses during the process of running and have higher requirements on the toughness of materials. Currently, the welding rotor is gradually prevalent for its saving cost and flexibility $[3,4]$. Narrow gap submerged arc welding (NGSAW) method is chosen to manufacture welding rotor for high production rate and low production cost $[5,6]$. However, in the reliability evaluation of equipment, fracture failure has become one of the main problems affecting the reliability of equipment. Therefore, the investigation on fracture

Available online at http://link.springer.com/journal/40195.

Haichao Cui

haichaocui@sjtu.edu.cn

Fenggui Lu

Lfg119@sjtu.edu.cn

1 Shanghai Key Laboratory of Materials Laser Processing and Modification, School of Materials Science and Engineering, Shanghai Jiao Tong University, Shanghai 200240, China toughness has always been a hot and difficult topic in engineering [7-10]. The fracture toughness parameters including elastic fracture and elastic-plastic fracture according to the plastic deformation ability of the material are mainly appointed to be the stress intensity factor $(K)[11,12]$, the energy release rate $(G)$ [13], $J$-integral [14] and crack tip open displacement (CTOD) [15], respectively.

A large number of studies have been performed on the reliable evaluation of $\mathrm{NiCrMoV}$ steel and fracture toughness test of weld metals in the past. Salemi and Abdollah-Zadeh [16] found that as the tempering temperature increased, the yield strength and tensile strength of NiCrMoV steel decreased, and the impact toughness was improved. Bandyopadhyay et al. [17] studied the evolution of precipitated phases of NiCrMoV steel with the changing service time. Wittig and Sinclair [18] reported that after tempering of $\mathrm{NiCrMoV}$ steel at $300-600{ }^{\circ} \mathrm{C}$, phosphorus would segregate to the original austenite grain boundaries, resulting in temper brittleness. Zhu et al. [19, 20] mainly studied that the crack growth resistance of $\mathrm{NiCrMoV}$ base metal decreased after aging treatment due to the coarsening of the structure and the precipitation of carbides, while the microstructure of the weld seam after aging treatment was more uniform, which improved the resistance of crack growth. Through the impact toughness test and the three-point bending test, Cai et al. [21] addressed that the impact toughness and fracture 
toughness of the interlayer reheating zone were poor, which was mainly related to the M-A component precipitation in the interlayer reheating zone. Abbasi et al. [22, 23] found that NiCrMoV steels showed significantly higher strength and lower ductility than $\mathrm{MnCrB}$ steel because of the small additions of alloying elements and different prior austenite grain sizes. In addition, the tempering resistance of $\mathrm{NiCr}$ MoV steel was higher compared to $\mathrm{NiCrSi}$ steel, which was mainly ascribed to the effect of $\mathrm{V}$-addition. By this token, the fracture toughness is closely related to the microstructure. According to our previous research, the addition of minor Ti element in the weld metal decreased the threshold of fatigue crack growth due to the presence of fine acicular ferrite and smaller size prior austenite grains [24]. Hence, it is worth deeply researching whether the addition of minor Ti element produces significant effects on the fracture toughness through the experimental test.

In this study, the microstructures of two NiCrMoV weld metals were characterized due to the introduction of trace elements by using different welding fluxes in NG-SAW, and its effect on the fracture toughness $\left(J_{0.2}\right)$ was discussed in this study. Furthermore, the size and quantity of inclusions in Ti-containing and Ti-free welds were taken to analyze the influence of microstructure on crack initiation and growth during fracture toughness test. Finally, the effect of large grain orientation difference on the propagation of crack was discussed by means of electron back-scattered diffraction (EBSD).

\section{Experimental}

\subsection{Experimental Materials}

The base metal was NiCrMoV steel, and $2 \mathrm{CrMoV}$ was employed as the filler metal, and the chemical compositions of base and filler metals are given in Table 1. In order to improve the welding efficiency and ensure the welding quality, narrow gap submerged arc welding (NG-SAW) was adopted. The multi-layer and multi-pass method was utilized in the welding process. Two different fluxes, A and B, were chosen as the fluxes of submerged arc welding, respectively. Compared with A flux, B flux reduces the Si and Mn elements and increases the Ti element in the weld metal. The chemical compositions of weld metals manufactured by two kinds of flux are listed in Table 2.

\subsection{Microstructure Analysis}

Optical microscope (OM, Zeiss, Axio Imager A2 m) was used to observe the microstructure of the welded joints after 30-s immersion with 5\% nitrate alcohol. Field emission scanning electron microscope (SEM, JSM 7800F) was used to observe the morphology of weld metal and analyze the distribution and composition of precipitated phases. The orientation difference and phases distribution near the crack were analyzed by using an electron back-scattered diffraction (EBSD, NOVA Nano SEM 230).

\subsection{Fracture Toughness Test}

Compact tensile (CT) specimens were applied to test the fracture toughness for WM of the welded joint. The specimen should ensure that the crack propagates through the multi-layer and multi-pass weld metal at the same time. Meanwhile, considering to make sure that the crack can propagate in special microstructure, the side grooves with depth of 0.1 times the specimen thickness were machined on both sides of the specimen. The sampling location and the size of compact tensile specimen are shown in Fig. 1a, b, respectively.

Firstly, the fatigue pre-crack was required and $K$ (stress intensity factor)-reduction method was used, where $K_{\max }=28 \mathrm{MPa} \mathrm{m}^{0.5}$, the fatigue load cycle ratio was set as $R=0.1$ ( $R$ is the minimum peak force divided by the maximum peak force) and the fatigue frequency is $6 \mathrm{~Hz}$. And then the specimens were loaded at the speed of $0.3 \mathrm{~mm} /$ min, and the load $(F)$ and the load direction displacement $(q)$ were recorded in real time to obtain the force-displacement curve. After finishing the load-displacement test, the secondary fatigue test was conducted to clearly identify
Table 1 Chemical compositions of base and filler metals (wt\%)

Table 2 Chemical compositions of weld metals manufactured by two kinds of flux (wt\%)

\begin{tabular}{llllllllllll}
\hline Elements & $\mathrm{C}$ & $\mathrm{Si}$ & $\mathrm{Mn}$ & $\mathrm{P}$ & $\mathrm{S}$ & $\mathrm{Cr}$ & $\mathrm{Mo}$ & $\mathrm{V}$ & $\mathrm{Ni}$ & $\mathrm{Ti}$ & $\mathrm{Fe}$ \\
\hline Base & $\leq 0.30$ & 0.14 & 0.19 & 0.004 & $\leq 0.15$ & 2.21 & 0.68 & 0.06 & 2.11 & - & Bal. \\
Filler & 0.09 & 0.21 & 1.41 & 0.006 & 0.002 & 0.57 & 0.51 & - & 2.23 & - & Bal. \\
\hline
\end{tabular}

\begin{tabular}{llllllllllll}
\hline Elements & $\mathrm{C}$ & $\mathrm{Si}$ & $\mathrm{Mn}$ & $\mathrm{P}$ & $\mathrm{S}$ & $\mathrm{Cr}$ & $\mathrm{Mo}$ & $\mathrm{V}$ & $\mathrm{Ni}$ & $\mathrm{Ti}$ & $\mathrm{Fe}$ \\
\hline A flux & 0.067 & 0.352 & 1.431 & 0.007 & 0.004 & 0.612 & 0.454 & 0.008 & 2.226 & - & $\mathrm{Bal}$ \\
B flux & 0.063 & 0.225 & 1.293 & 0.006 & 0.003 & 0.636 & 0.488 & 0.004 & 2.266 & 0.006 & Bal. \\
\hline
\end{tabular}


(a)

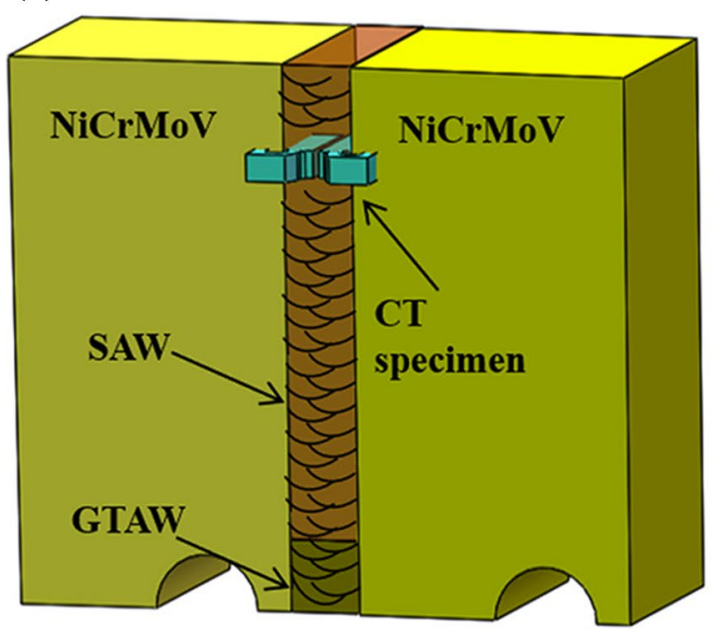

(b)

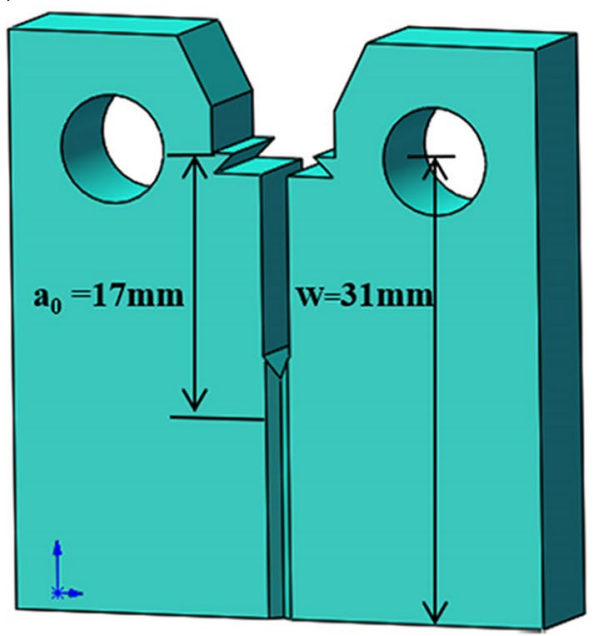

Fig. 1 Schematic diagram of processing direction $\mathbf{a}$ and geometry size $\mathbf{b}$ of compact tensile specimen

the corresponding crack extension $(\Delta a)$. Finally, the crack extension length was measured with the nine-point average method.

\section{Results and Discussion}

\subsection{Microstructure Characterization}

Figure 2 shows the profile of weld joint and the microstructure in the middle of the weld metal of A flux and B flux, respectively. The microstructures in the middle of weld manufactured by A flux are granular bainite (GB), acicular ferrite (AF) and tempered M-A component or tempered martensite islands (Tempered M-A/M). In Fig. 2e, the protruding massive structures with different sizes are granular bainites. Yokomizo et al. [25] and Cheng and $\mathrm{Wu}$ [26] have studied the morphology of acicular ferrite. In three-dimensional space, acicular ferrite grows around inclusions in lathy shape. Detailed microstructure of acicular ferrite is shown in Fig. 2e; it can be observed that acicular ferrite grew radially centered on spherical inclusions obviously in the weld and interlocked with each other. As shown in Fig. 2f, due to the thermal effect in multi-layer and multi-pass welding process, the martensite islands, which are dark blocky structures in the metallographic photograph in Fig. 2c, decomposed and a large amount of carbides were precipitated along both the edge and the inside of the islands. The microstructures in the middle of weld manufactured by B flux are also the mixed microstructures of granular bainite, acicular ferrite and tempered martensite islands. From Fig. 2d, g, it is seen that compared with weld manufactured by A flux, the microstructures of weld manufactured by B flux are uniform and fine.

\subsection{Evaluation on Fracture Toughness $J_{0.2}$}

According to the experimental data obtained, the $J-\Delta a$ resistance curves of the weld manufactured by A flux and B flux are shown in Fig. 3, and the intersection of $0.2 \mathrm{~mm}$ offset line and resistance curve is the fracture toughness value $\left(J_{0.2}\right)$ of weld metal. For A flux, the $J-\Delta a$ resistance curve is $J=5+469.58(\Delta a)^{0.57}$ and $J_{0.2}$ is $232.78 \mathrm{~kJ} / \mathrm{m}^{2}$. For B flux, the $J-\Delta a$ resistance curve is $J=5+756.88(\Delta a)^{0.65}$ and $J_{0.2}$ is $364.08 \mathrm{~kJ} / \mathrm{m}^{2}$.

\subsection{Characterization on Fracture Morphology}

Figure 4 shows the fracture morphology of weld metal manufactured by A flux and B flux. In Fig. 4b, c, the edge of the fracture is mainly shallow tearing dimple, and the middle dimple is equiaxed, which is under the condition of nearly three-direction stress state. Figure $4 \mathrm{~d}$ reveals that there are inclusions or second-phase particles at the bottom of the dimple, and the existence of voids is observed in the fracture except the dimple, which is a typical microporous aggregate fracture.

It can be observed that the dimples on the edge of the fracture are shallow, showing a slight tear shape, and the dimples are dense, forming a continuous network as shown in Fig. 4f. Considering that this is related to the uniform and fine granular bainite structure in the weld manufactured by $\mathrm{B}$ flux, the deformation of the dimple in three directions is relatively uniform. Compared with the tearing dimples in Fig. 4b, dimples in Fig. 4f absorb more energy, resulting in higher fracture toughness of weld manufactured by B flux than that of A flux. 

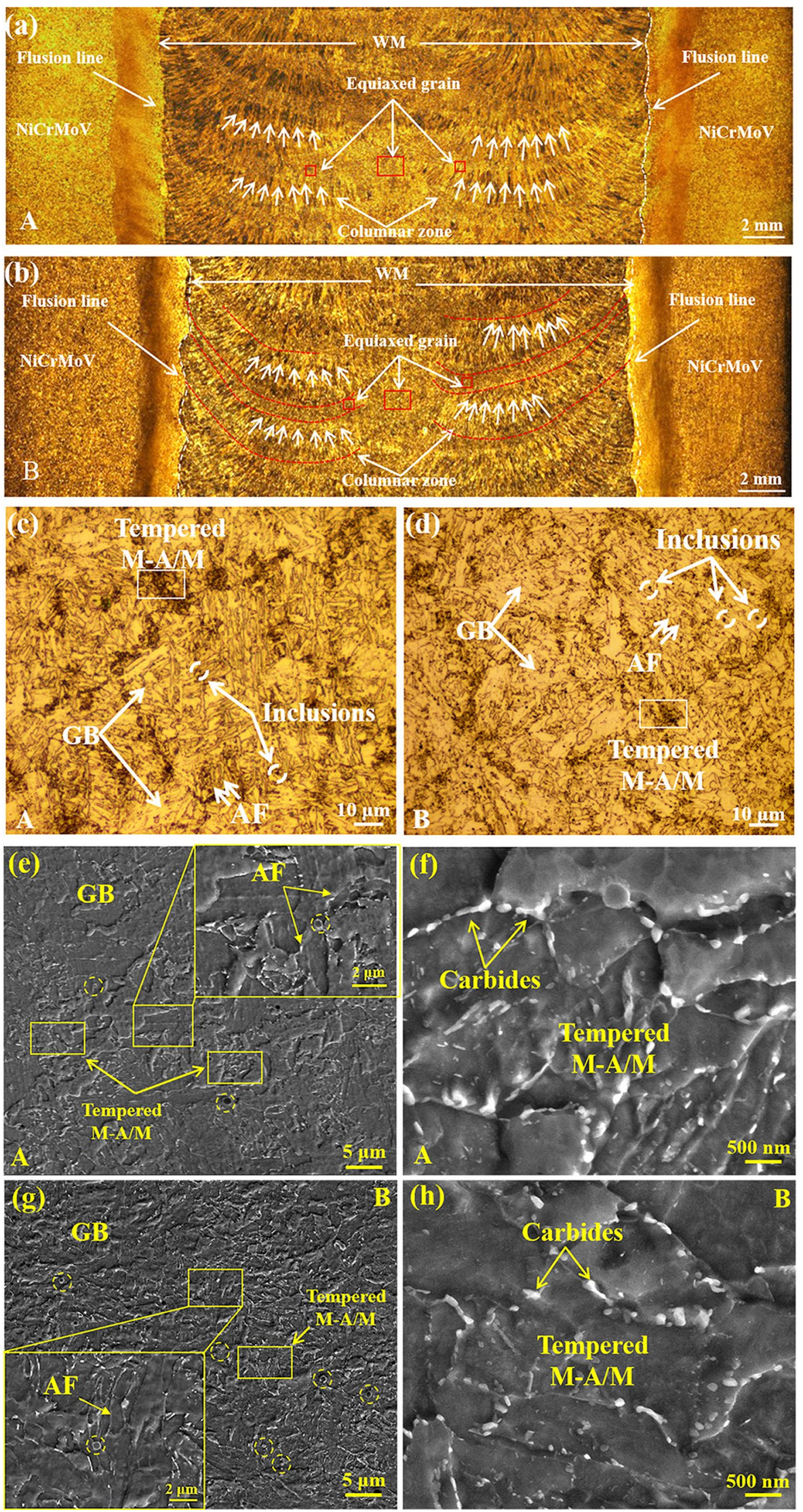
4Fig. 2 a Macro profile of weld joint with A flux, b macro profile of weld joint with B flux, $\mathbf{c}$ equiaxed crystals in the center of weld manufactured by A flux, $\mathbf{d}$ equiaxed crystals in the center of weld manufactured by B flux, e, f micromorphology of equiaxed crystals in the center of weld manufactured by A flux, $\mathbf{g}, \mathbf{h}$ micromorphology of equiaxed crystals in the center of weld manufactured by B flux

\subsection{Affecting Mechanism of Inclusion on Microstructure}

In the submerged arc welding, more deoxidizing elements such as $\mathrm{Mn}, \mathrm{Si}$ and $\mathrm{Al}$ are added to the flux to react with oxygen in the molten pool to form slags, resulting in a lot of granular impurities in the weld metal. The sizes of inclusions have a great influence on the properties of the weld metal. Larger inclusions are considered as a welding defect, which reduce the carrying capacity of weld. When the size of inclusions is small, according to the inert interfacial energy mechanism proposed by Ricks et al. [27], the inclusion surface can reduce the energy barrier and promote heterogeneous nucleation of acicular ferrite. The acicular ferrite has a high dislocation density, and the ferrite laths are alternately staggered, which can refine the intragranular structure and improve the resistance to crack growth. Therefore, it is very important to compare the inclusions in the welds of $\mathrm{A}$ and B fluxes.

Figure 5a, b shows the micro-morphologies of the weld metal of A flux and B flux, respectively, and acicular ferrite was found near the inclusions. In order to further obtain the content of the elements in the inclusions, Fig. 5c, d shows the spot scanning results of inclusions composition in the weld metal of A flux and B flux, respectively. The results show that Ti elements were detected in the inclusions of weld manufactured by B flux, while there was no Ti element in the inclusions of weld manufactured by A flux. It can be found that the spherical inclusions in two kinds of flux welds are mainly composed of oxides of $\mathrm{Al}, \mathrm{Si}$ and $\mathrm{Mn}$. The inclusions are rich in oxygen and poor in iron, which are the products of typical deoxidation reaction. It can also be seen that there are petal-like structures around the inclusions, which grow outward with the inclusions as nucleation centers and are typical acicular ferrite structures. This is mainly due to the addition of $\mathrm{TiO}_{2}$ to the $\mathrm{B}$ flux. As shown in Table 1, the content of Ti element in weld metal manufactured by B flux is $60 \mathrm{ppm}$, which is much more than that of A flux. Fattahi et al. [28] studied the effect of Ti element on the nucleation of acicular ferrite in submerged arc weld metal of lowcarbon steel and found that the content of acicular ferrite in weld increased with the increase in Ti nanoparticles in flux cored wire. Meanwhile, the oxides of Ti elements such as $\mathrm{Ti}_{2} \mathrm{O}_{3}$ [29], $\mathrm{TiO}_{2}$ [30] and $\mathrm{TiO}$ [31] are strong nucleating sites of ferrite. Evans [32] systematically studied the effect of Ti on the weld metal of C-Mn steel. The results showed that adding $30 \mathrm{ppm}$ to the weld metal was enough to form acicular ferrite.

Not only the composition of inclusions has an important influence on the formation of acicular ferrite, but also the size of inclusions affects the nucleation power of acicular ferrite. Image-Pro Plus software was used to calculate the inclusion diameter in the two kinds of welds. The statistical object is 10 SEM photographs magnified 5000 times, and the number of inclusions is more than 100.

Figure $5 \mathrm{e}, \mathrm{f}$ shows that the diameters of inclusions in both two welds are less than $1.2 \mu \mathrm{m}$, and the diameter distribution satisfies the normal distribution. For A flux, the average diameters are mainly distributed in the range of $0.3-0.7 \mu \mathrm{m}$, accounting for $87 \%$ of the total statistics. The average diameter is $0.5 \mu \mathrm{m}$, and the distribution density of inclusions is $2.8 \times 10^{3} / \mathrm{mm}^{2}$. The average diameter of inclusions in weld manufactured by B flux is mainly in the range of $0.4-0.8 \mu \mathrm{m}$, accounting for $85 \%$ of the total statistics. The average diameter is $0.6 \mu \mathrm{m}$, and the distribution density of inclusions is $3.5 \times 10^{3} / \mathrm{mm}^{2}$.

On the basis of a large number of experimental data, Lee [33] established the nucleation model of acicular ferrite which showed that the size of inclusions in favor of intragranular nucleation is $0.25-0.8 \mu \mathrm{m}$. From the Jye-Long formula, the relative nucleation ability is directly proportional to the average diameter of inclusions in the range of favorable nucleation size. Therefore, the nucleation ability of inclusions formed by B flux is higher than that of A flux.

\subsection{Crack Propagating Path}

The deflection of the crack is determined by the characteristics of microstructure. By analyzing the microstructure and orientation distribution near the crack path, the crack initiation position and propagation law can be found. Figure 6 shows the macroscopic feature of the crack paths of two kinds of weld metal. From Fig. 6c, d, it is seen that the crack propagation path of weld metal manufactured by A flux is relatively smooth, and the path of weld metal manufactured by B flux presents many zigzag profiles. From the microscopic view, there are many block chain structures around the crack path of weld with A flux, and the structures around the crack path of weld with B flux are relatively small.

Figure $6 \mathrm{e}$ outlines the crack propagating path with a curve and the difference between the two outlines in the yellow rectangular frame is significant. Curve coordinates in the yellow rectangular frame are extracted by using MATLAB, and the degree of dispersion of the curve is analyzed. The data variance of the contour $X$ direction corresponding to A flux is 25.81 , the range is 120.03 , while the data variance of the contour $X$ direction corresponding to B flux is 40.69 , and the range is 147.82 . Therefore, the height difference (range) of crack surface between the two 
(a)

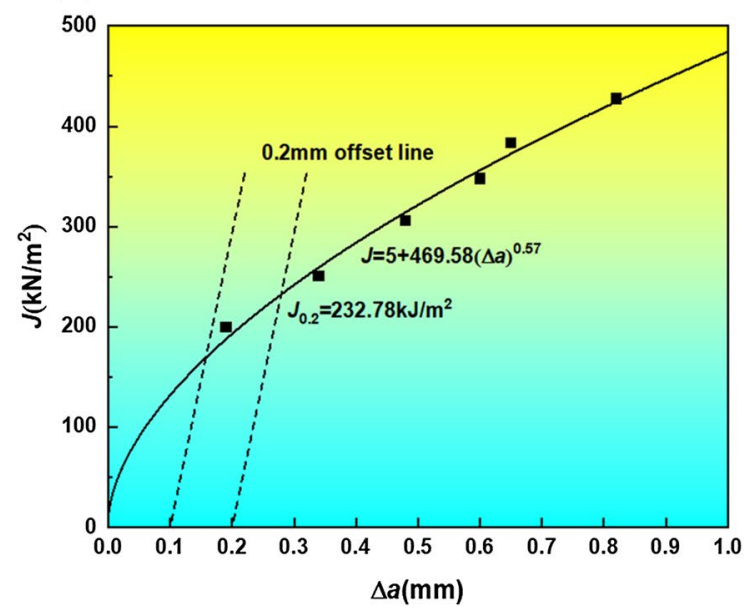

(b)

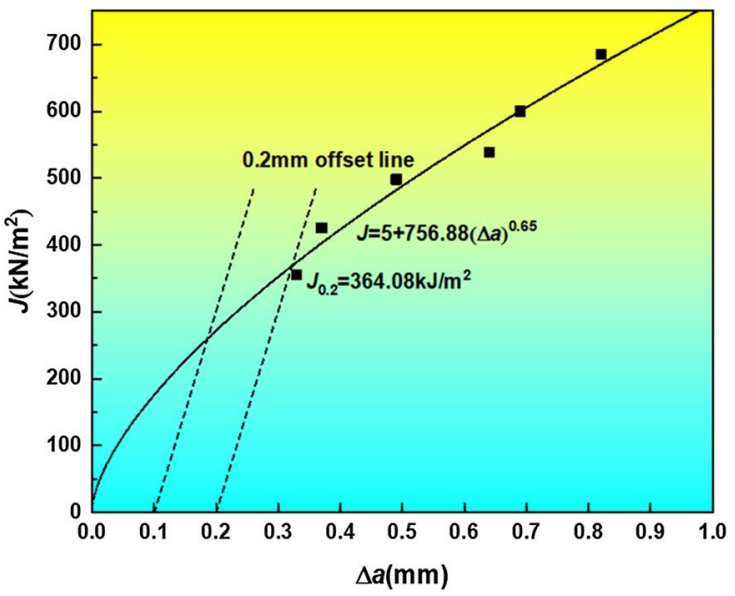

Fig. 3 Crack propagation curve $(J-\Delta a)$ of weld metal with flux A and flux B: a $J-\Delta a$ resistance curves of A flux, b $J-\Delta a$ resistance curves of B flux

welds is similar, but the variance shows that the number of deviations on the crack path of weld with B flux is more, so surface area of crack and the energy needed for propagation are larger resulting in better toughness.

The corresponding crack paths of the two welds were further observed by SEM, and the results are shown in Fig. 7. As shown in Fig. 7a, it can be found that there are black holes near the crack propagation path of weld metal manufactured by A flux, which can be seen that the fracture mode is typical microporous aggregation fracture. Tempering structure is found on the crack path as shown in Fig. $7 b$, and bright white carbides are distributed in the interior and the edge of tempered structure. Cracks propagate along the edge of tempered island structure where black holes can be observed, which is the microscopic feature of carbides separated from matrix under external load. Figure 7c, d shows the details of crack path deflection. Cracks deflect when they propagate along tempered structure to the block structure, and propagate along the edge of block structure. The block structure is martensite island with high strength, which has a certain hindrance effect on crack growth and increases the surface area of cracks.

From Fig. 7e, it is found that secondary cracks occur in the main crack path. Figure $7 \mathrm{f}$ shows that the ends of secondary cracks are bifurcated, and then deflect after encountering block island structures. Figure $7 \mathrm{~g}$, h shows the phenomenon that the crack deviates from the original crack surface when it extends to the block martensite island, especially the crack shown in Fig. $7 \mathrm{~g}$ deviates nearly $90^{\circ}$ near the island structure. More crack deflection and secondary cracks are found in the crack path of weld metal with B flux, so the fracture toughness of weld metal with B flux is higher.
Figure 8 is EBSD analysis results for fracture toughness specimens of welds manufactured by A flux and B flux, respectively. The grain orientation difference distribution along the crack propagation path is shown in Fig. 8a, d, respectively, where the green line represents the small-angle grain boundary less than $15^{\circ}$, and the black line represents the large-angle grain boundary greater than $15^{\circ}$. Figure 9 gives the statistical results of grain boundary orientation. The results show that small-angle grain boundaries are dominant in weld with A flux, while small-angle grain boundaries in weld with B flux decrease, and the proportion of large-angle grain boundaries increases, which is mainly related to the increase in acicular ferrite content in weld with B flux. Moreover, the size of inclusions has a great influence on the growth mode of ferrite [34]. The smaller inclusions $(0.3-0.5 \mu \mathrm{m})$ are mostly located inside the ferrite laths or at the interface of ferrite. Because the ferrite laths are thick, the grain boundary angle is smaller. When the size of inclusions is in the range of $0.5-0.8 \mu \mathrm{m}$, the surface area of inclusions increases and many ferrites can grow around the inclusions as nucleation sites. The ferrite laths interlock with each other and restrain the growth largely. Therefore, the ferrite laths formed are smaller and the grain boundary angle is larger.

Figure $8 b$, e is the distribution of the inverse pole figures on the crack path. The inverse pole figures mainly reflect the size of the orientation difference between adjacent grains. From Fig. 8b, we can see that the orientation difference of the upper A region of the crack path is smaller than that in the B region, so the crack deflects greatly. However, in Fig. 8e, it is found that the grain orientation difference of weld with B flux is uniformly distributed on the whole and the number of crack deflections is more. Figure $8 \mathrm{c}, \mathrm{f}$ is strain distributions along the 

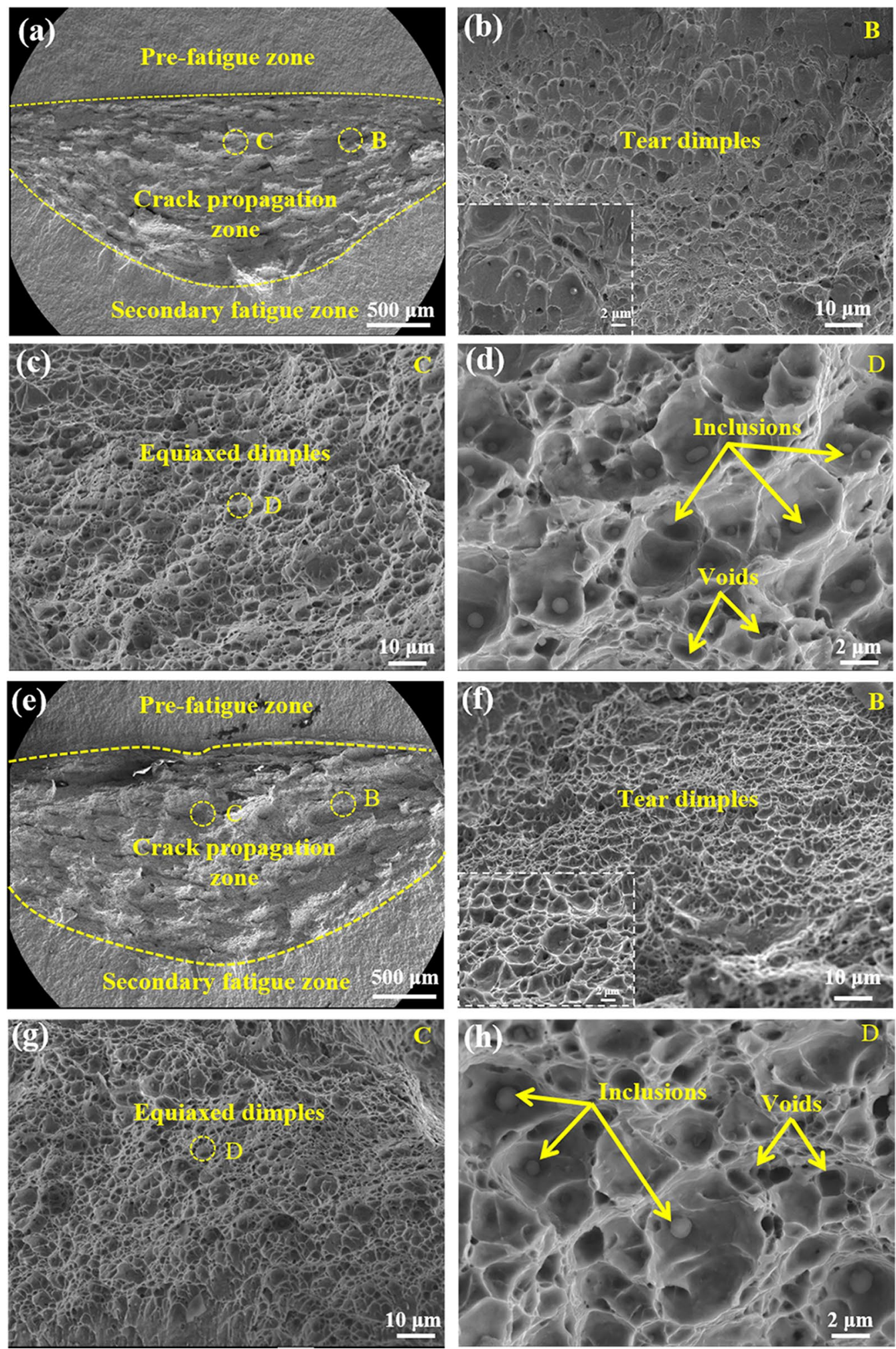

Fig. 4 Fracture morphologies of weld metal: a overall fracture surface of weld metal with A flux, $\mathbf{b}$ tear dimples marked as B in a, c equiaxed dimples marked as $\mathrm{C}$ in $\mathbf{a}, \mathbf{d}$ detailed feature of equiaxed dimples marked as $\mathrm{D}$ in $\mathbf{c}, \mathbf{e}$ overall fracture surface of weld metal with B flux, $\mathbf{f}$ tear dimples marked as B in $\mathbf{e}, \mathbf{g}$ equiaxed dimples marked as $\mathbf{C}$ in $\mathbf{e}, \mathbf{h}$ detailed feature of equiaxed dimples marked as D in $\mathbf{g}$ 

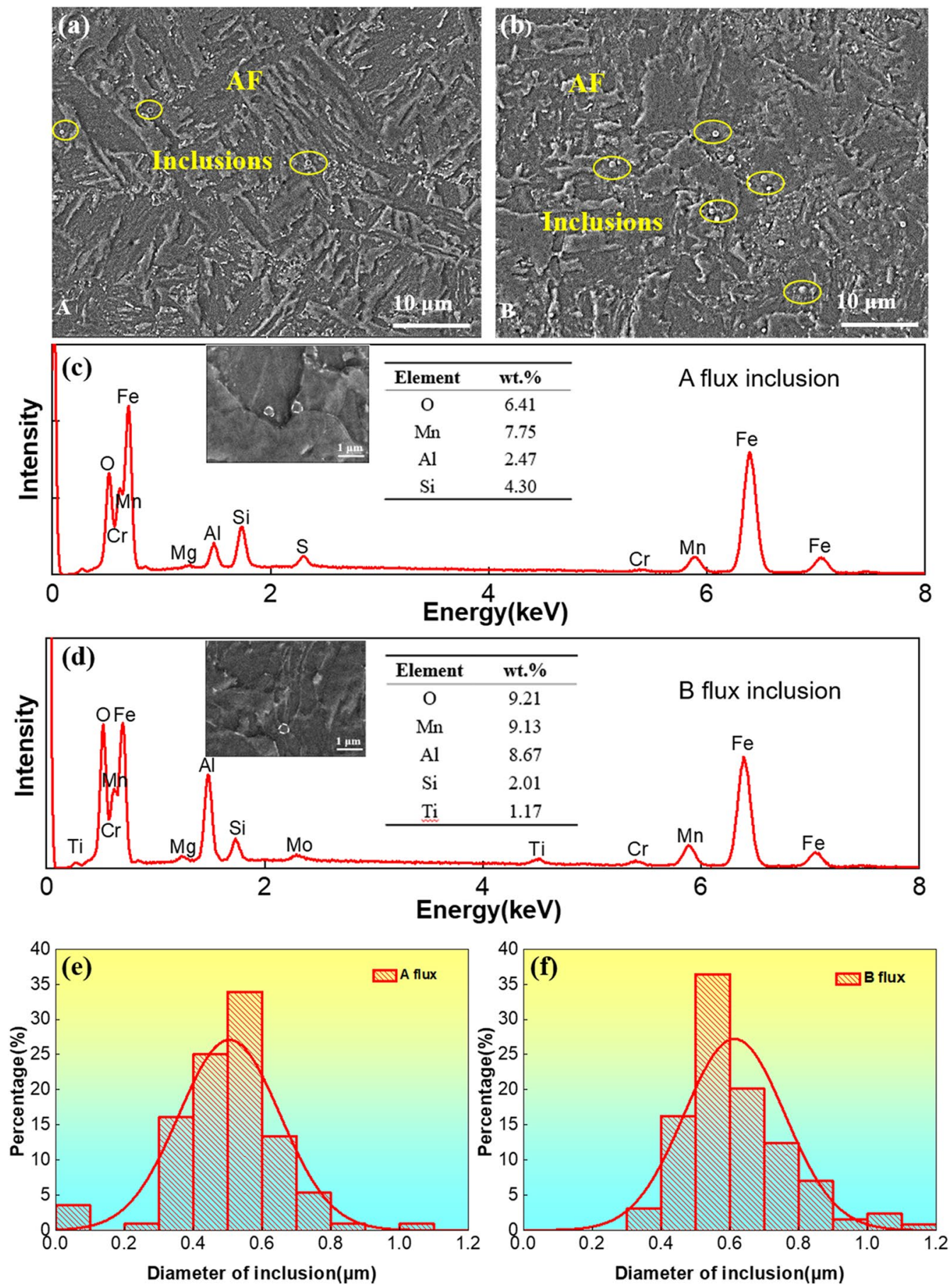

Fig. 5 a Inclusions morphology of weld metal with A flux, b inclusions morphology of weld metal with B flux, c compositions of inclusion in weld metal with A flux, $\mathbf{d}$ compositions of inclusion in weld metal with B flux, $\mathbf{e}$ inclusion diameter statistics for weld manufactured by A flux, $\mathbf{f}$ inclusion diameter statistics for weld manufactured by B flux

crack paths corresponding to the two fluxes, respectively. It can be found that the peak strain mainly occurs around the fine massive structure, where $\mathrm{C}$ region is in the figure and the $\mathrm{D}$ region with obvious directivity produces less strain. Therefore, the strain distribution in the weld metal with A flux is not uniform, while the strain distribution in the weld metal with B flux exists more homogeneously and the microstructure with good deformability occupies a higher proportion. 

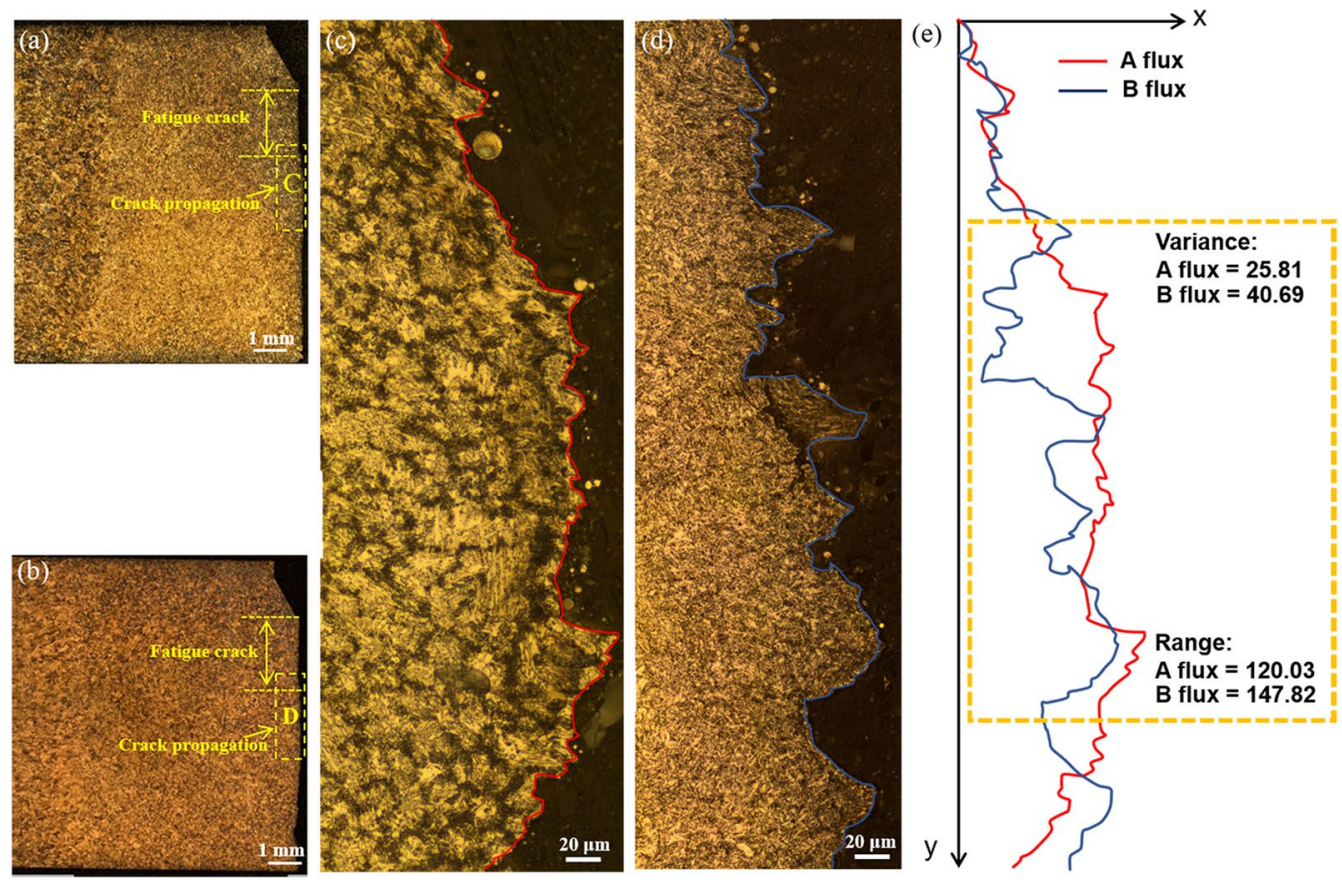

Fig. 6 Crack propagation path of different fluxes: a notch morphology of weld with A flux, b notch morphology of weld with B flux, $\mathbf{c}$ crack propagation path of weld with A flux, $\mathbf{d}$ crack propagation path of weld with B flux, $\mathbf{e}$ crack profile

\section{Conclusions}

In this study, the effects of trace elements on fracture toughness and microstructure of weld metal through Tifree and Ti-containing fluxes in NG-SAW were systematically investigated. The main conclusions are drawn as follows:

(1) The fracture toughness of $J_{0.2}$ for Ti-free flux weld and Ti-containing flux weld is $232.78 \mathrm{~kJ} / \mathrm{m}^{2}$ and $364.08 \mathrm{~kJ} /$ $\mathrm{m}^{2}$, respectively, showing that the trace element Ti in weld metal has great influence on fracture toughness.
(2) The size and distribution of inclusions in Ti-containing are more beneficial to nucleate the acicular ferrite and promote the acicular ferrite bundles interlock with each other. The microstructure of ferrite bundle and M-A/M islands inhibited the crack propagation inducing more bifurcations and deflections in Ti-containing weld metal.

(3) More large-angle grain boundaries and distribution of grain orientation difference by EBSD indicated that Ti-containing weld metal possessed more resistance to crack propagation, accounting for the crack path deflection. The strain distribution also showed that Ticontaining weld metal absorbed more energy, which also illustrates the higher fracture toughness. 

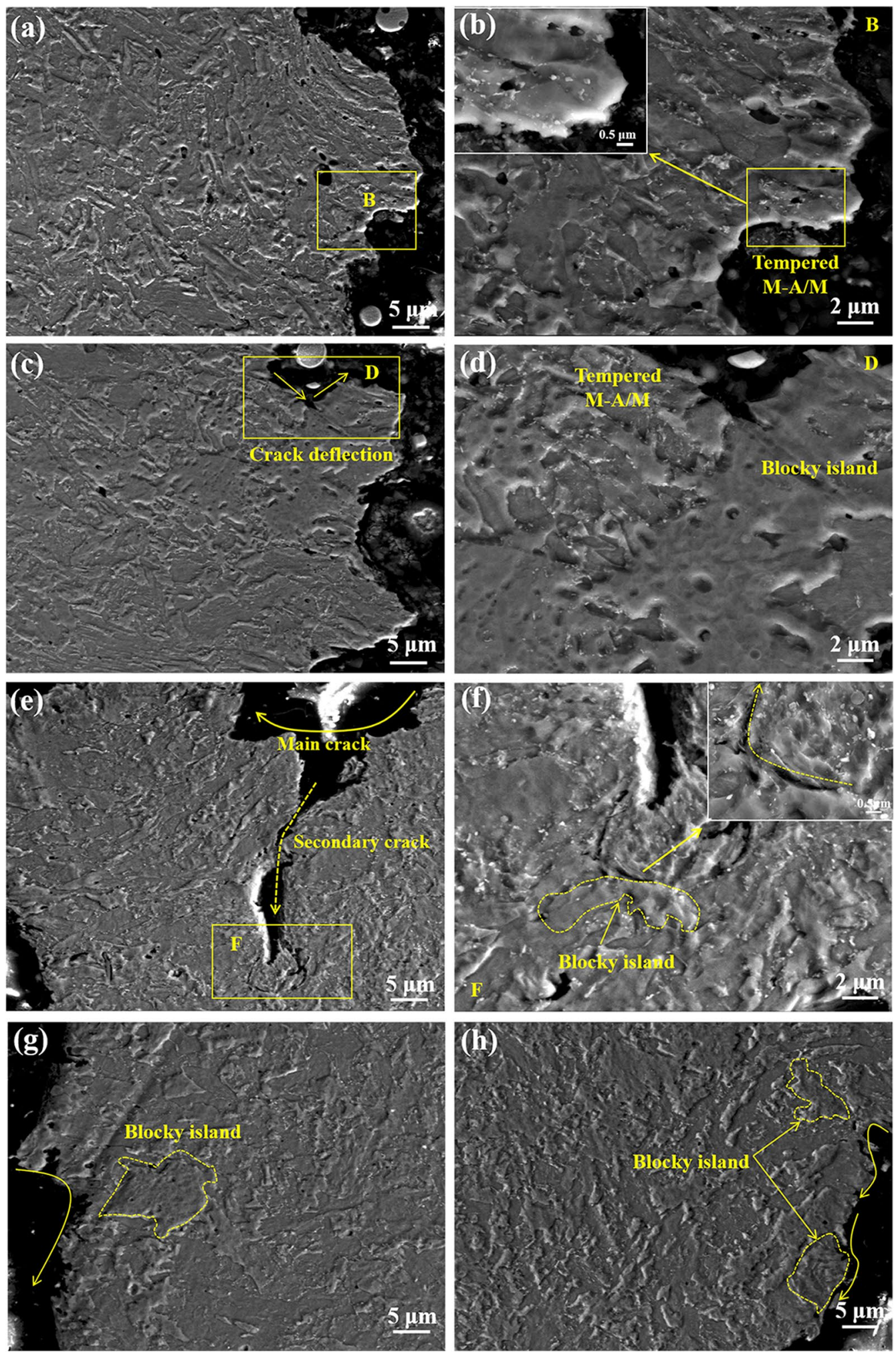

Fig. 7 Microscopic morphologies of crack propagation path: a crack propagation path for WM with A flux, $\mathbf{b}$ detailed feature of the B area in $\mathbf{a}$, $\mathbf{c}$ crack deflection for WM with A flux, $\mathbf{d}$ detailed feature of the D area in $\mathbf{c}$, $\mathbf{e}$ crack propagation path for WM with B flux, $\mathbf{f}$ detailed feature of the $\mathrm{F}$ area in $\mathbf{e}, \mathbf{g}, \mathbf{h}$ blocky island for WM with B flux 
(a)

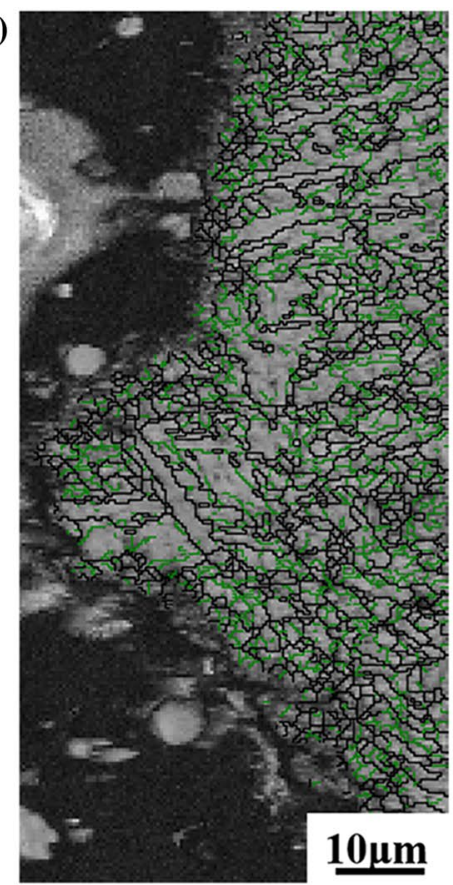

(d)

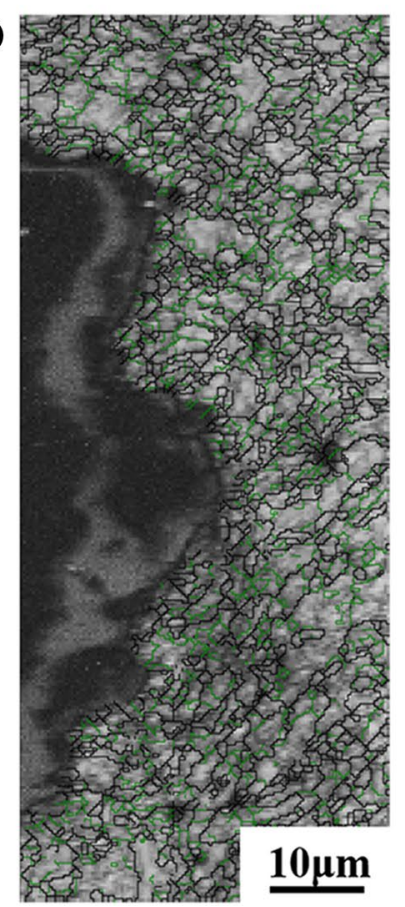

(b)

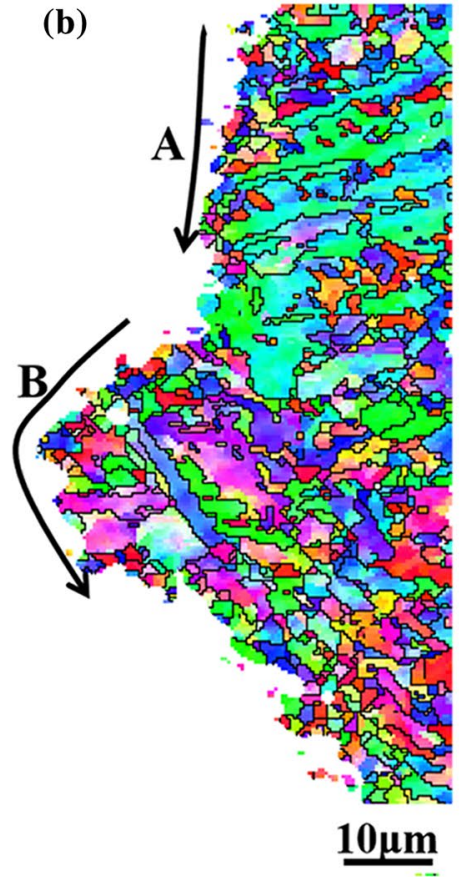

(e)

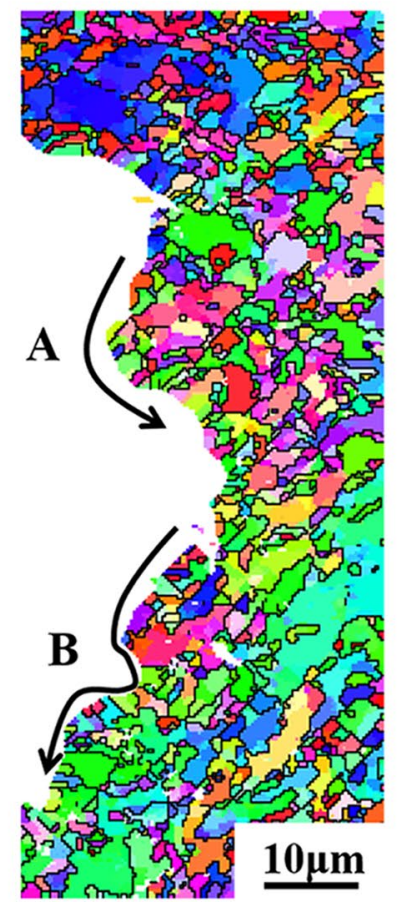

(c)

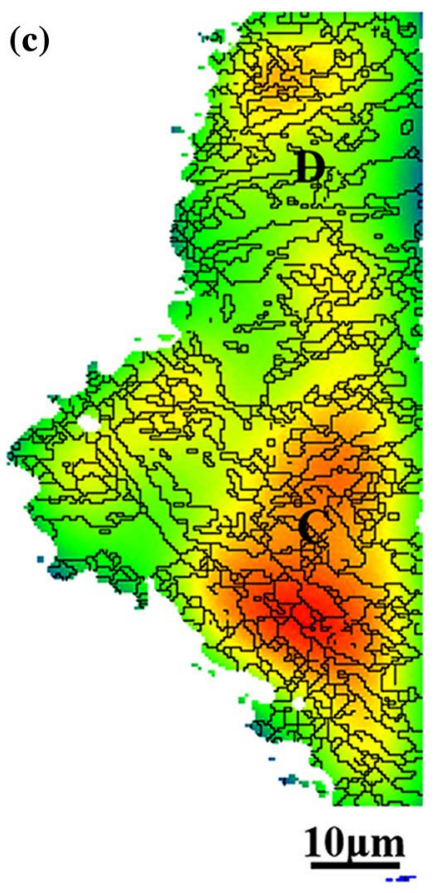

(f)

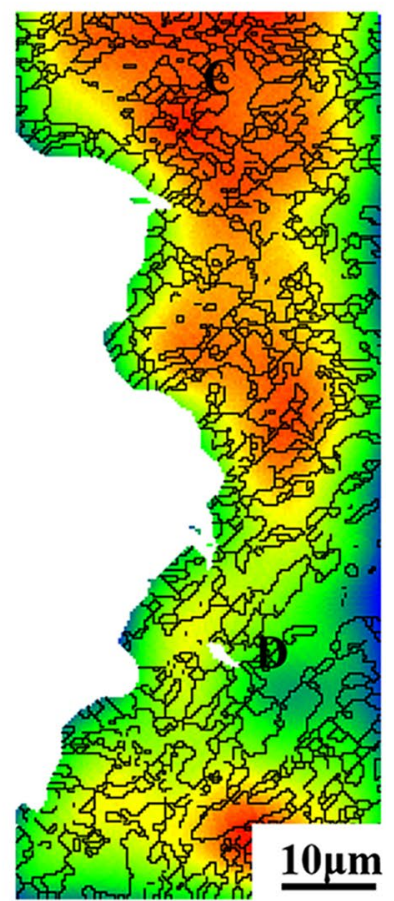

Fig. 8 EBSD analysis results of crack propagation path for WM by A flux: a band contrast and grain boundary (green $5^{\circ}<\theta<15^{\circ}$, black $\theta \geq 15^{\circ}$ ), $\mathbf{b}$ inverse pole figure, $\mathbf{c}$ strain distribution, for WM by B flux: $\mathbf{d}$ band contrast and grain boundary $\left(\right.$ green $5^{\circ}<\theta<15^{\circ}$, black $\theta \geq 15^{\circ}$ ), $\mathbf{e}$ inverse pole figure, $\mathbf{f}$ strain distribution 

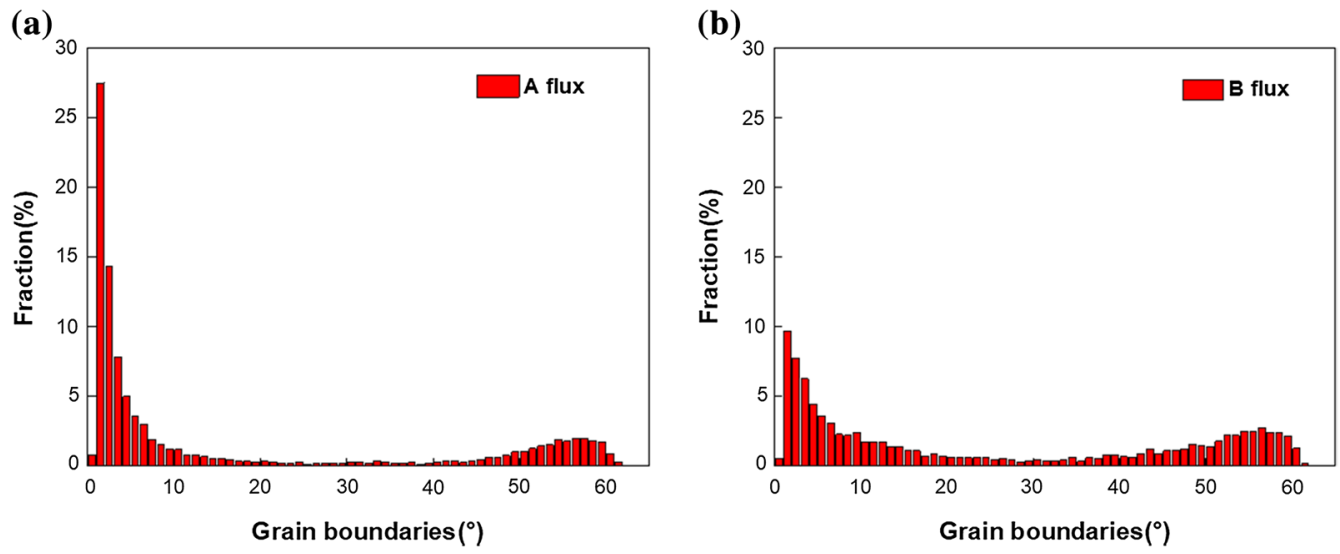

Fig. 9 Distribution of grain orientation along crack propagation path: a A flux and b B flux

Acknowledgements The authors gratefully acknowledge the financial support by the National Natural Science Foundation of China (Nos. 51675336 and U1660101) and the experimental supports by the Instrumental Analysis Center of Shanghai Jiao Tong University (SJTU).

\section{References}

[1] L. Tan, J. Zhang, D. Zhuang, C. Liu, Nucl. Eng. Des. 273, 47 (2014)

[2] Y. Zhang, H.Y. Jing, L.Y. Xu, Y.D. Han, L. Zhao, X.S. Xie, Q.H. Zhu, Acta Metall. Sin. (Engl. Lett.) 32, 638 (2019)

[3] C. Shao, F. Lu, Z. Li, Y. Cai, P. Wang, Y. Ding, J. Mater. Res. 31(2), 292 (2016)

[4] Q. Guo, F. Lu, X. Liu, R. Yang, H. Cui, Y. Gao, Mater. Sci. Eng. A 638, 240 (2015)

[5] F. Lu, X. Liu, P. Wang, Q. Wu, H. Cui, X. Huo, J. Mater. Res. 30(13), 2108 (2015)

[6] L. Tan, L. Zhang, J. Zhang, D. Zhuang, Fusion Eng. Des. 89(4), $456(2014)$

[7] S. Yang, Z. Yang, X. Ling, J. Mater. Res. 29(15), 1675 (2014)

[8] Y.L. Xue, S.M. Li, H. Zhong, L.P. Li, H.Z. Fu, Acta Metall. Sin. (Engl. Lett.) 28(4), 514 (2015)

[9] V. Kumar, I. Singh, B. Mishra, R. Jayaganthan, Acta Metall. Sin. (Engl. Lett.) 27(2), 359 (2014)

[10] M.K. Pathak, A. Joshi, K. Mer, R. Jayaganthan, Acta Metall. Sin. (Engl. Lett.) 32(7), 845 (2019)

[11] G. Anstis, P. Chantikul, B.R. Lawn, D. Marshall, J. Am. Ceram. Soc. 64(9), 533 (1981)

[12] R.O. Ritchie, J.F. Knott, J.R. Rice, J. Mech. Phys. Solids 21(6), 395 (1973)

[13] G. R. Irwin, J. Appl. Mech. 24, 351 (1957)
[14] J. Ast, T. Przybilla, V. Maier, K. Durst, M. Göken, J. Mater. Res. 29(18), 2129 (2014)

[15] S.G. Lee, D.H. Lee, S.S. Sohn, W.G. Kim, K.K. Um, K.S. Kim, S. Lee, Mater. Sci. Eng. A 697, 55 (2017)

[16] A. Salemi, A. Abdollah-Zadeh, Mater. Charact. 59(4), 484 (2008)

[17] N. Bandyopadhyay, C.L. Briant, E.L. Hall, Metall. Trans. 16(5), 721 (1985)

[18] J.E. Wittig, R. Sinclair, Steel Res. Int. 75(1), 47 (2004)

[19] M.L. Zhu, D.Q. Wang, F.Z. Xuan, Mater. Charact. 87(1), 45 (2014)

[20] Y.N. Du, M.L. Zhu, X. Liu, F.Z. Xuan, J. Mater. Process. Technol. 226, 228 (2015)

[21] X. Liu, Z. Cai, X. Deng, F. Lu, J. Mater. Res. 32(16), 1 (2017)

[22] E. Abbasi, Q. Luo, D. Owens, Mater. Sci. Eng. A 725, 65 (2018)

[23] E. Abbasi, Q. Luo, D. Owens, Acta Metall. Sin. (Engl. Lett.) 32(1), 74 (2019)

[24] X.Y. Guo, L.F. Zhao, X. Liu, F.G. Lu, Int. J. Fatigue 120, 1 (2019)

[25] T. Yokomizo, M. Enomoto, O. Umezawa, G. Spanos, R.O. Rosenberg, Mater. Sci. Eng. A 344(1-2), 261 (2003)

[26] L. Cheng, K.M. Wu, Acta Mater. 57(13), 3754 (2009)

[27] R.A. Ricks, P.R. Howell, G.S. Barritte, J. Mater. Sci. 17(3), 732 (1982)

[28] M. Fattahi, N. Nabhani, M. Hosseini, N. Arabian, E. Rahimi, Effect of Ti-containing inclusions on the nucleation of acicular ferrite and mechanical properties of multipass weld metals. Micron 45(2), 107 (2013)

[29] J.S. Byun, J.H. Shim, Y.W. Cho, Scr. Mater. 48(4), 449 (2003)

[30] S. Ohkita, Y. Horii, ISIJ Int. 35(10), 1170 (1995)

[31] T. Yamada, H. Terasaki, Y.I. Komizo, ISIJ Int. 49(7), 1059 (2009)

[32] G. Evans, Weld. Res. Abroad 38(8-9), 13 (1992)

[33] J.L. Lee, Acta Metall. Mater. 42(10), 3291 (1994)

[34] Q. Jiang, Y.J. Li, J. Wang, L. Zhang, Mater. Sci. Technol. 27(10), $1565(2011)$ 